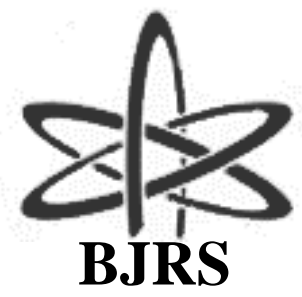

BRAZILIAN JOURNAL

$\mathrm{OF}$

RADIATION SCIENCES

08-03A (2020) 01-12

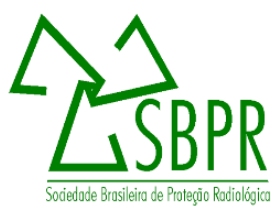

\title{
Decommissioning cost estimation for a multiple reactor site with interdependent plants: case study using a new management tool and top-down approach
}

\author{
Deiglys Borges Monteiro, João Manoel Lousada Moreira, José Rubens Maiorino \\ Federal University of $A B C$ \\ deiglysbmonteiro@gmail.com
}

\begin{abstract}
In the end of operational life, a nuclear power plant should be decommissioned to release its site for a new purpose. The decommissioning cost estimation is part of the decommissioning plan, which also include the decommissioning strategy definition. The cost estimation is performed by management tools, most of them according the bottom-up approach. However, this approach usually requires large quantities of data and detailed knowledge of the site conditions and the project phases, which are often unknown in the project beginning, requiring the adoption of several assumptions. Otherwise, the top-down approach requires less data or assumptions, and the project details is known as it became mature. Due to this, the top-down approach is a better approach for cost estimation during planning phase than the bottom-up. Despite it, most part of management tools found in literature to cost estimation are structured according the bottom-up approach. To suppress this lack, recently a new management tool was developed according the top-down approach, being able to estimate the decommissioning cost of nuclear power plants for budget/bid purposes. This work aims to present the cost estimation to decommissioning a multiple reactor power site with similar characteristics of the Brazilian ones, which would be used as benchmark. The results demonstrated that the interdependencies among the plants are important and affects significantly the cost to decommissioning each plant. This work is part of a research that is under course in which several strategies alternatives would be evaluated.
\end{abstract}

Keywords: top-down, multiple reactor, benchmark, cost estimation, budget. 


\section{INTRODUCTION}

At the end of its operational life, a Nuclear Power Plant (NPP) should be decommissioned to reduce the site radioactivity and risks as well as allow to release the site to a repurpose $[1,2]$. The decommissioning is a very complex, large, lengthen and costly process, which should be carefully planned to facilitate its execution and minimize the inherent risks and reduce its cost [2]. The decommissioning process could be executed according different strategies, such immediate dismantling, deferred dismantling or a hybrid strategy among these two [2]. The choose of the strategy that better meets the project needs is driven mainly by the site characteristics, strategical plan of the operator company, future uses of the site, environment/social/economics issues, regulatory framework, policy, among others [2]. In case of multiple reactor sites, also the interdependencies among the plants should be carefully considered, especially if the plants have different operational/shutdown schedules, aiming to minimize the number of resources and equipment mobilization [1,2].

In Brazil, there is only a nuclear power site under operation [1-5]. The site is named as Central Nuclear Almirante Álvaro Alberto (CNAAA) and is strategically located at coordinates (23.007095, -44.457390), at Angra dos Reis county, Rio de Janeiro state, among the three major Brazilian power and economic centers: São Paulo, Rio de Janeiro and Belo Horizonte [2-4]. Some of the main characteristics of the CNAAA site are: it is a multiple reactor site, with three power plants powered by Pressurized Water Reactors (PWR), two operating (Angra 1 and Angra 2) and a third NPP under construction (Angra 3) [2]. Since these plants shares part of the resources required to its operation and supporting facilities (such as operational and management teams, laboratories, workshops, storerooms, etc), as well as systems/structures (only Angra 1 and Angra 2 actually shares systems/structures, such as the hot water discharge from condensers cooling), they are considered interdependent. As consequence, the decommissioning of one plant has the potential to interfere with the operations of the other plants (commercial operation of Angra 2 or construction of Angra 3) [2-4]. This issue is still more important considering the start/operating schedule of the CNAAA plants: in Brazil, a new plant starts operation at about 20 to 25 years, which is an unique/abnormal schedule in the world [2-4]. 
Besides the schedule, also the decommissioning cost is an important parameter that should be carefully evaluated before the process starts because the financial guarantees must be sufficient to cover the entire process, avoiding the need to demobilize teams/equipment and mobilize them again after a time, which implies in extra costs. On the other hand, the process cost is directly affected by the decommissioning strategy once it affects its duration [2]. In this manner, the strategy definition/project duration and cost estimation are part of a coupled problem. Several management tools that are found in literature perform the cost estimation according the bottom-up approach. These tools are often structured according to the Work Breakdown Structure (WBS) approach [1, 2]. Despite of this approach being adequate from the engineering point of view due to the high level of detail, its use require a very large database, previous experience in field or assumptions that not always represents the site characteristics, the process objectives or strategical planning of the operator, since the process beginning [1, 2, 6-11]. On the other hand, the top-down approach requires a reduced quantity of data in the process beginning, despite some previous experience is still desirable, and thus, is preferable in the project beginning instead the bottom-up approach. Despite of it, only recently a mathematical model for decommissioning cost estimation, structured according the top-down approach, have being developed. This mathematical model is named AvDescom, which is part of a management tool named Ger-Descom $[1,2]$.

This work is a deployment of the research in which the Av-Descom model and the Ger-Descom tool were developed. In this work, one of the strategies proposed by Monteiro [2] and its cost estimation are presented and discussed considering the multiple reactor approach. The site considered as case study is similar to CNAAA site in terms its schedule, number of plants at the site, plants power and interdependencies among them. The schedule considered is a hybrid strategy among the immediate and deferred dismantling strategies. The results shown that the interdependencies have the potential to change the process costs significantly comparing with the results obtained by Monteiro [2] in the strategies presented by the author. The rest of this work is organized as follows: section 2 describes the work methodology and governing equations. Section 3 details the boundary conditions. Section 4 presents the results and a discussion regarding them. Section 5 presents the conclusions and final remarks, followed by the acknowledges and references. 


\section{MATERIALS AND METHODS}

In the present work, the Av-Descom model is used to estimate the decommissioning cost of a hypothetical multiple reactor site with three interdependent plants. The Av-Descom model have being initially proposed and detailed by $[1,2]$. For a multiple reactor site with 3 interdependent plants, the decommissioning cost could be estimated according the equation (1) [2].

$$
\mathrm{CD}_{\text {Sitio }}=\left(\sum_{\mathrm{i}=1}^{3} \mathrm{CD}_{\mathrm{i}}\right)
$$

in which CDi is the decommissioning cost of each plant at the site. This cost could be calculated by using the equation (2).

$$
\mathrm{CD}_{\mathrm{i}}=\left(\sum_{\mathrm{i}=1}^{5} \mathrm{c}_{\mathrm{Ei}}+\mathrm{C}_{\mathrm{TRR}}+\mathrm{C}_{\mathrm{DRR}}+\mathrm{C}_{\mathrm{TRC}}+\mathrm{C}_{\mathrm{DRC}}\right)
$$

in which CEi is the cost of each of phase, considering 5 decommissioning steps or phases $[1,2]$. According to Monteiro [2], the phases to be considered in the decommissioning are: Planning (Phase 1), Transition (Phase 2), SAFSTOR period (Phase 3), Decontamination and Dismantling (Phase 4), Process Finishing (Phase 5). $\mathrm{C}_{\mathrm{TRR}}$ is the transport cost of the radioactive waste. $\mathrm{C}_{\mathrm{DRR}}$ is the disposal cost of the radioactive waste. $\mathrm{C}_{\mathrm{TRC}}$ is the transport cost of the conventional waste. $\mathrm{C}_{\mathrm{DRC}}$ is the disposal cost of the conventional waste. These phases and Av-Descom model details could be accessed in the works of Monteiro et al. [1, 2].

\subsection{Assumptions}

In this work we consider the assumptions made by Monteiro et al. [1]. However, since in this $\underline{a}$ multiple reactor site is considered as a case of study, also the assumptions made by Monteiro [2] are required. The assumptions considered in the present work are detailed as follows:

- The case of study is a multiple reactor site, with 3 interdependent plants arranged similarly as the CNAAA plants [2]; 
- The NPPs considered are named NPP1, NPP2 and NPP3. The benchmark plants of each of these plants are: Angra 1 to NPP1, Angra 2 to NPP2 and Angra 2/3 to NPP3;

- The decommissioning process is not interrupted once it starts [1];

- The financial guarantees offered must be enough to cover the entire process, avoiding interrupting it due to lack of funds [1];

- A disposal facility must be able to receive the wastes from decommissioning (conventional and radioactive wastes) $[2,12]$;

- No new developments of technology and process required to perform the decommissioning activities/tasks according ALARA principles (As Low As Reasonable Achievable) must be required, since they must be already in use in plants operation and maintenance [2];

- The Phases 4 and 5 of the decommissioning process would be executed sequentially. The process chronogram is show in the Gant graphic form in Figure 1;

- There is no previous experience in field. Despite of it, since the plants to be decommissioned has the same type o reactor (PWR) and the decommissioning would be performed sequentially, some knowledge would be gained, contributing to reduce the time required and risks involved in the execution of decommissioning activities. It was considered the following percentages to each plant to be decommissioned [2]: $5 \%$ for the second plant, $10 \%$ for the third plant (considering the decommissioning cost of the first plant as reference);

- At the end of the decommissioning process, the site would be released for unrestricted use;

- The men-hour cost considered represents the Brazilian context in terms of technological development, working laws and rights, etc [1,2];

- The difficult factors and contingency considered are the same considered by Monteiro et al. $[1,2]$;

- All the costs related to shared resources/activities are allocated within the NPP3 cost estimation (the last plant to be shut and start the decommissioning process, and that could keep supporting these costs). 
Figure 1: Chronogram of Strategy 8.

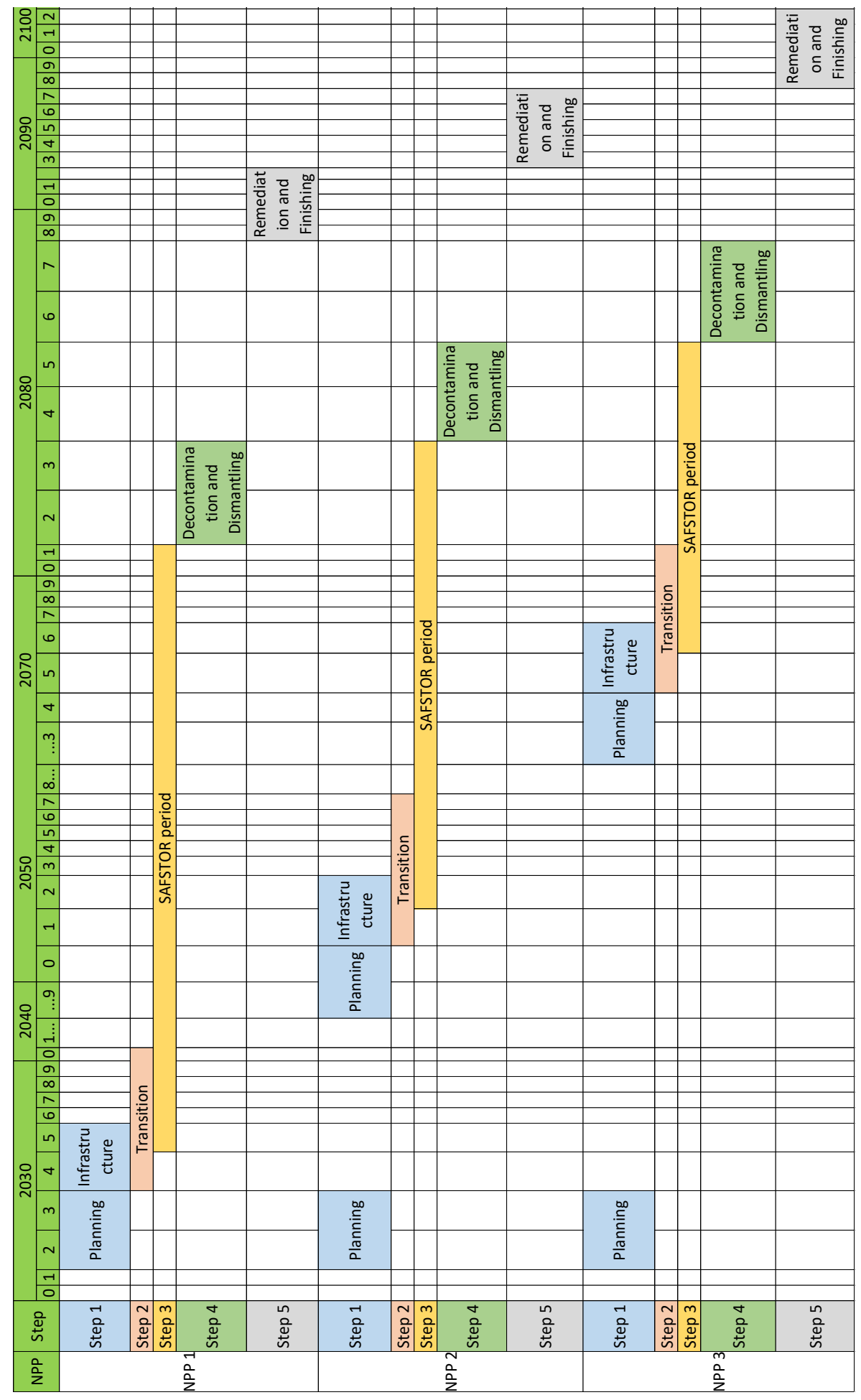




\section{RESULTS AND DISCUSSION}

Considering the assumptions of section 2.1 and the schedule of Figure 1, the decommissioning cost of each plant and of the site (the total cost of the process) was obtained using the Av-Descom model. These costs are available in Table 1. The percentage contribution of each activity to each plant cost and to the site cost is given graphically in Figure 2 while Figure 3 show the contribution of each plant cost to the total cost.

Table 1: Decommissioning cost estimation for the case study site: multiple reactor site.

Costs are given in millions of US\$

\begin{tabular}{ccccc} 
Steps & NPP1 & NPP2 & NPP3 & Site \\
\cline { 2 - 5 } Step 1 & 14,4 & 19,5 & 169,2 & 203,1 \\
Step 2 & 15,5 & 15,2 & 14,4 & 45,2 \\
Step 3 & - & - & 138,5 & 138,5 \\
Step 4 & 102,3 & 112,9 & 134,0 & 349,1 \\
Step 5 & - & - & 5,8 & 5,8 \\
Conventional waste management & 7,6 & 8,6 & 8,6 & 24,8 \\
Radioactive waste management & 1,6 & 1,8 & 22,2 & 25,6 \\
Radioactive waste transport & 15,8 & 18,1 & 18,5 & 52,4 \\
Radioactive waste disposal & 16,4 & 33,4 & 33,4 & 83,2 \\
& $\mathbf{1 7 3 , 5}$ & $\mathbf{2 0 9 , 5}$ & $\mathbf{5 4 4 , 6}$ & $\mathbf{9 2 7 , 6}$ \\
\hline
\end{tabular}


Figure 2: Steps/tasks contribution to the project cost.

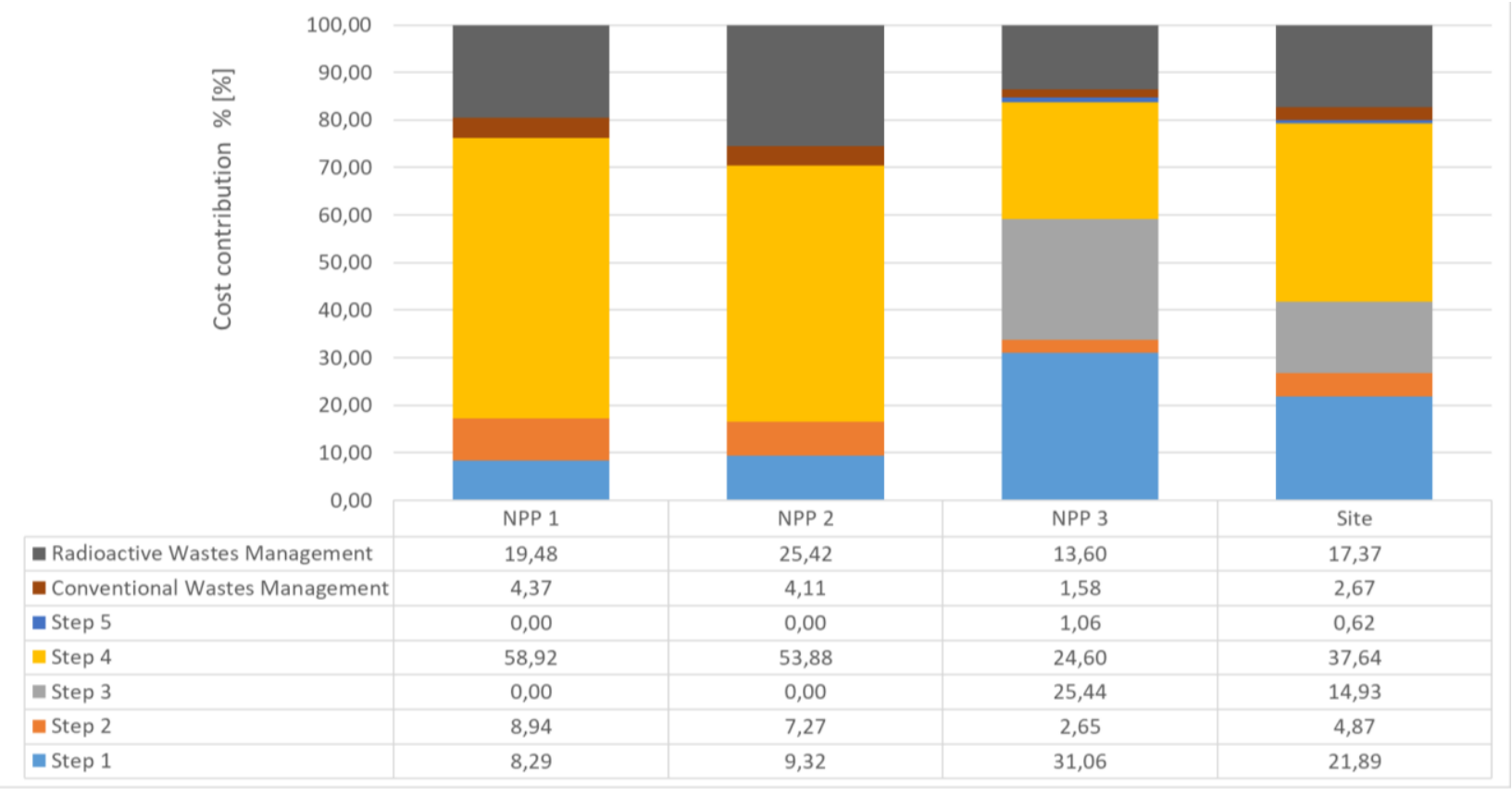

Figure 3: Costs contribution of each NPP to the site cost - Strategy 8.

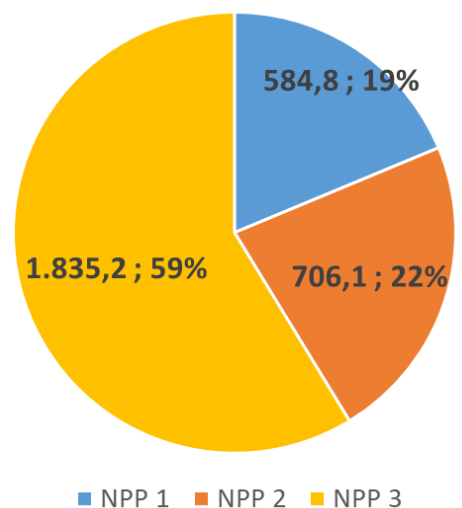

As can be observed in Table 1 and Figure 3, NPP3 contributes mostly to the process cost (59\%). This is due to the schedule considered and the fact that most of the costs are allocated to the estimated costs for this plant. On the other hand, the NPPs 1 and 2 contributes each one to about only $20 \%$ of the total cost. Notwithstanding, it is possible to observe in Table 1 and Figure 2 that the major cost phase of NPPs 1 and 2 is step 4, while steps 1 and 3 contribute approximately with the same value 
to each of these plants' costs. If considered that NPPs 2 and 3 are essentially equals to each other, it is expectable that their costs be approximately the same. However, this is not observed. This is due the interdependencies among the plants and the shared costs being allocated mostly in the NPP3 cost estimation. Thus, it could be concluded that the interdependencies should be properly considered once it significantly affects the process schedule and its $\underline{\text { costs. }}$.

Regarding NPP3, it could be observed that the Phase 3 represents an important cost, even considering that its decontamination and dismantling is proposed to occur after a short SAFSTOR period. This occur since the costs of physical security, maintenance and radiological protection teams that are keep in force during the NPPs 1 and 2 SAFSTOR period are all allocated in the NPP3 cost estimation (which explains also why the cost estimation of NPPs 1 and 2 have no cost associated with the Phase 3).

Regarding the Waste management, it could be an important cost for NPPs 1 and 2, contributing roughly to about $25 \%$ for NPP1 and $30 \%$ for NPP2 (conventional and radioactive wastes). On the other hand, as consequence of the other activities' costs, the importance of this cost is reduced for NPP3 and for the site cost cotribution. It should be observed also that, for the three plants and for the site, this cost is mostly associated to the radioactive wastes than to the conventional wastes.

Regarding the Phases 2 and 5, despite their importance to the decommissioning process, it could be observed that they contribute only marginally to all plant's costs, especially NPP3, as well as for the total cost (the site cost). This occur due the learning from a project to the next and since the tasks performed in these phases do not involve to deal with high radioactive/contaminated materials (with exception of the fluids drainage and fuel removal from the reactors vessel in the Phase 2).

It is important also to observe that the cost to decommissioning the NPP1 differs only slightly with respect to NPP2, despite them have very different power. Besides the interdependencies, this occur also due to the learning from a project to the next. In this manner, it is possible to conclude that the power of the plant does not play a significant role in a multiple reactor site as it plays in case of a standalone plant. On the other hand, it is possible to observe that the project duration is the second most important issue to be cosidered (after the plants interdependencies), since it plays a significant role with respect to the process cost too.

Considering the results and the discussion presented in this section, it could be concluded that in a multiple reactor site there is important issues to be considered that differs from the case of a 
standalone plant, which similar studies could be found widely in literature. For a multiple reactor site, the interdependencies is the most important issue, followed by the project length and learning obtained from a process to the next. Instead occur for a standalone plant, the plant power does not play a significant role with respect to the total cost.

\section{CONCLUSION}

In this work the decommissioning cost estimation of a multiple reactor nuclear power site with interdependent plants was presented. The results demonstrated that the interdependencies affects significantly the process cost and the contribution of each phase, followed by the process duration. On the other hand, the plant's power does not play a significant role as it plays for a standalone plant. The cost of Decontamination and Dismantling activity is the most important to all plants and to the site, while the planning is most important for the first plants and not for the last plant. The same is valid for the waste management activity, with the radioactive waste being the major cost associated to this activity. Finally, this work presented a benchmark proposal for the operator company of the Brazilian site (CNAAA site) evaluate when the decommissioning project takes place.

\section{ACKNOWLEDGMENT}

Authors wish to acknowledge UFABC and FAPESP to support this work.

\section{REFERENCES}

[1] MONTEIRO, D.B.; MOREIRA, J.M.L.; MAIORINO, J.R.; A new management tool and mathematical model for decommissioning cost estimation of multiple reactors site. Progress in Nuclear Energy, v.114, p.61-83, 2019. 
[2] MONTEIRO, D.B.; Decommissioning of Brazilian nuclear centrals: proposal of a management tool for decommissioning costing. $\mathrm{PhD}$ Thesis. UFABC, Santo André - SP, 2017.

[3] MONTEIRO, D.B.; MOREIRA, João M.L.; MAIORINO, José R.; Decommissioning strategy and schedule for a multiple reactor nuclear power plant site. In: Proceedings of INAC 2015, ABEN, XIX Encontro Nacional de Física de Reatores - ENFIR. São Paulo, Brasil, Oct. 4-9, 2015.

[4] MONTEIRO, D.B.; MOREIRA, João M.L.; MAIORINO, José R.; Brazilian nuclear power plants decommissioning plan based on multiple reactor decommissioning approach. In: Proceedings of INAC 2015, ABEN, XIX Encontro Nacional de Física de Reatores - ENFIR. São Paulo, Brasil, Oct. 4-9, 2015.

[5] MONTEIRO, D.B.; MOREIRA, J.M.L.; MAIORINO, J.R.; Metodologia e equações para estimar o custo de descomissionamento de plantas nucleares brasileiras; In: Proccedings of IX Congresso Brasileiro de Planejamento Energético, Florianópolis, Brazil, Ago. 25-27, 2014.

[6] OECD/NEA - Organization for Economic Cooperation and Development/ Nuclear Energy Agency. International Structure for Decommissioning Costing of Nuclear Installations, OECD/NEA, 2012.

[7] PMI - Project Management Institute. PMBook Guide Chapter 1: Introduction. $3^{\text {rd }}$ edition, Norma ANSI/PMI 99-001-2004, ISBN: 1-930699-74-3 (Brochure-Português-Brasil), 3 ed., p. 3-18, PMI, Pennsylvania, EUA, (2004).

[8] FRAJNDLICH, R.; Considerations about the decommissioning of the IEA-R1 research reactor and the future of its facilities after shutdown. $\mathrm{PhD}$ Thesis. Instituto de Pesquisas Energéticas e Nucleares, IPEN, Autarquia associada à Universidade de São Paulo, USP, São Paulo, 2014. 
[9] US-NRC - US Nuclear Regulatory Commission. Changes in Decommissioning Waste Disposal Costs at Low-Level Waste Burial Facilities. NRC U.S.NRC, NUREG/CR-1307, Rev.15, 2012.

[10] ZACHAR, M.; DANIŠKA, V.; NEČAS, V.; Improved analytical methodology for calculation assessment of material parameters in nuclear installation decommissioning process. Progress in Nuclear Energy, v.53, p.463-470, 2011.

[11] US-NRC - US Nuclear Regulatory Commission. Estimating Pressurized Water Reactor Decommissioning Costs, A User's Manual for the PWR Cost Estimating Computer Program (CECP) Software, Draft Report for Comment. Division of Regulatory Applications, U.S.NRC, NUREG/CR-6054 PNL-8497, NRC, 1993.

[12] PINHO, B.E.; An initial plan proposal for the transition period after permanent shutdown of Angra 1 nuclear power plant until the safe storage. Master Thesis. Rio de Janeiro - RJ. COPPE - UFRJ, 2018. 